\title{
Enhancement of Investment Decision Making Using Real Options with Application to Advanced Process Control Project
}

\author{
Anukoon Asawachatroj $^{1, \mathrm{a}}$, David Banjerdpongchai ${ }^{2, \mathrm{~b}}$, and Pornanong Busaratragoon ${ }^{3, \mathrm{c}}$ \\ 1 Technopreneurship and Innovation Management Program, Chulalongkorn University, 254 Phayathai \\ Road, Pathumwan, Bangkok 10330, Thailand \\ 2 Department of Electrical Engineering, Faculty of Engineering, Chulalongkorn University, 254 Phayathai \\ Road, Pathumwan, Bangkok 10330, Thailand \\ 3 Department of Banking and Finance, Chulalongkorn Business School, Chulalongkorn University, 254 \\ Phayathai Road, Pathumwan, Bangkok 10330, Thailand \\ Email: aAnukoon.a@gmail.com, bbdavid@chula.ac.th (Corresponding author), cpornanong@acc.chula.ac.th.
}

\begin{abstract}
Feasibility study is one of the most important parts of decision making for project investment. Current industrial approach to estimate benefit of advanced process control (APC) is based on the conventional estimation techniques, namely, statistical analysis, net present value, and payback period. These conventional approaches can answer the investment either 'Go' or 'No Go'. The gap analysis reveals that economic uncertainties and inflexibility of decision criteria are the issues required improvement on the decision making process. In this paper, we apply a real options approach to develop option to defer analysis as part of the proposed feasibility study of APC project. We demonstrate improvement of the proposed method with a case study on ethylene plant in Thailand. The result shows that option to defer can answer 'when to defer' and 'when to invest'. Hence, this approach enhances the investment decision making under economic uncertainties and provides flexible decision criteria.
\end{abstract}

Keywords: Advanced process control, economic assessment, investment decision making, real options, option to defer.

ENGINEERING JOURNAL Volume 18 Issue 3

Received 19 July 2013

Accepted 30 October 2013

Published 10 July 2014

Online at http://www.engj.org/

DOI:10.4186/ej.2014.18.3.37 


\section{Introduction}

Industrial Automation and Control System (IACS) has increasingly influenced the industrial processes. To invest in the multi-million dollar project, the management must carefully consider business justification to make a right decision. The project team consists of process engineer, electrical engineer, control engineer, industrial engineer, supply chain, project manager and so on. The team has to make a series of important decisions to select appropriate technologies starting from field instrument and control system and to align with process licensing criteria. Previously, the core function of IACS technology includes Distributed Control Systems (DCS) and Safety Instrumented Systems (SIS). However, DCS with the Proportional, Integral and Derivative (PID) controllers have limited capability and cannot perform process optimization, such as maximizing the cost function subject to operating constraints. Over the past decades, optimization technology has played an important role to increase economic benefit. Advanced Process Control (APC) employs optimization techniques to develop superior performance of process operation and fulfill DCS capability. The most popular APC technology is Model Predictive Control (MPC) which makes use the plant dynamics to predict the output response and improve the process behavior, especially, reference tracking. There has been significant development of MPC in the recent years, such as multi-objective optimization for MPC [1], etc.

Conventional approach of benefit estimation such as discounted cash flow (Net Present Value, NPV) or payback period cannot capture management flexibility to adapt in response of uncertainties in economic situation. This is because the conventional approach assumes a scenario to a certain business environment. Hence, the conventional approach can answer only 'Go/No Go' question. However, the real world is characterized as interaction, dynamics and uncertainties. Bauer and Craig [2] report that "while process control technology has evolved in the past decades, estimation techniques for the economic benefit that results from advanced control solutions appear to have remained static." When new information arrives and uncertainty of economic conditions are known, the management can make decision the right strategy of investment among possible available options as well as to react in alternatives decision to mitigate any possible losses. This managerial flexibility decision is acting like financial options and known as real options. The objective of this paper is to improve the economic assessment (EA) method for APC feasibility study subject to economics uncertainties. The contribution on this research is to enhance the investment decision making criteria using the real options approach, especially, option to defer analysis, and demonstrate its effectiveness by applying the proposed criteria to APC project of an ethylene plant in Thailand. In particular, the proposed method can handle the economics uncertainties and advise the period which the investment should be deferred and the period which investment should be made.

The paper is organized as follows. In section 2, we review the current EA method for APC and identify the gap from the existing approach. In section 3, we discuss about real options approach. The key question is "how to apply option to defer to enhance the APC project investment decision". To perform an initial validation, we select a case study to apply the option to defer and compare the result with that from payback period method in section 4. Finally, the conclusion of the research and future work are given in section 5 .

\section{Economic Assessment of APC}

In general, APC ensures performance improvement in process operation. In view of process performance, applying APC to the process leads to a $50 \%$ reduction of output variance [2] and an increase of throughput by approximately $3-5 \%$ [3]. To explore economic benefits, we investigate EA of APC.

\subsection{Economic Assessment Technique}

Economic assessment for APC project has been reported in [4-7]. Many researches are interested in the techniques to measure the variance reduction by using economic performance functions [8-10]. The MPC economic performance evaluation has been studied in [11] and the performance index for assessing the benefits of process control has proposed in [12]. The performance index can be divided into major cost functions, namely, quadratic function, linear function with constraints.

The conventional approach of economic assessment technique from process control is to reduce the variance in the process and to shift the operation point close to the performance limit based on the process 
specification shown in [13] and analyzed with statistical data in [14]. Most of the industrial estimations utilize the technique called "the Same Percentage Rule". From [2, 13-16], we can classify the economic assessment into three main methods.

1. Statistical Analysis. The average value of the process constraint will be increased to gain the benefit of standard deviation reduction. This method is also known as the Same Percentage Rule.

2. Dynamic Simulation. The method will simulate a model of the plant as a base case and then optimize the multiple variables.

3. Human Expertise. Use the rules of thumb or the experience from previous APC project.

Next, we explore the Same Percentage Rule as it is still used in the industry. Define the mean of process variable $\overline{P V}$ as follows.

$$
\overline{P V}=\frac{\sum_{i=1}^{n} P V_{i}}{n}
$$

where $P V_{i}=$ the $i$ th value of the process variable, and

$n=$ the number of samples.

Then, the standard deviation is defined as

$$
S D=\sqrt{\frac{\sum_{i=1}^{n}\left(P V_{i}-\overline{P V}\right)^{2}}{n-1}}
$$

Next, define the percentage reduction of standard deviation $r$ as

$$
r=S D_{A P C} / S D_{\text {base }}
$$

where $S D_{A P C}=$ standard deviation after implementing APC, and $S D_{\text {base }}=$ standard deviation of base case.

Estimate the change of $\overline{P V}$ after implementing APC by calculating $\overline{P V}$ in (1), $S D_{\text {base }}$ in (2) and $S D_{A P C}$ in (3). Therefore, we can determine $\Delta \overline{P V}$ as follows.

$$
\Delta \overline{P V}=\left(P V_{\text {spec }}-\overline{P V}\right)\left(1-\frac{S D_{A P C}}{S D_{\text {base }}}\right)
$$

The limitation of the same percentage rule is that the user has to specify the value $r$ in Eq. (3). However, this value is varying within a certain range, like the dynamic business situation. Thus, the same percentage rule cannot handle the situation when there is uncertainty in the business information.

\subsection{Feasibility Study Process of APC}

The implementation of APC project is comprised of seven major steps [3] whereas the APC feasibility study process involves the first three steps. Figure 1 displays feasibility study process of APC project that is typically adopted in automation industries.

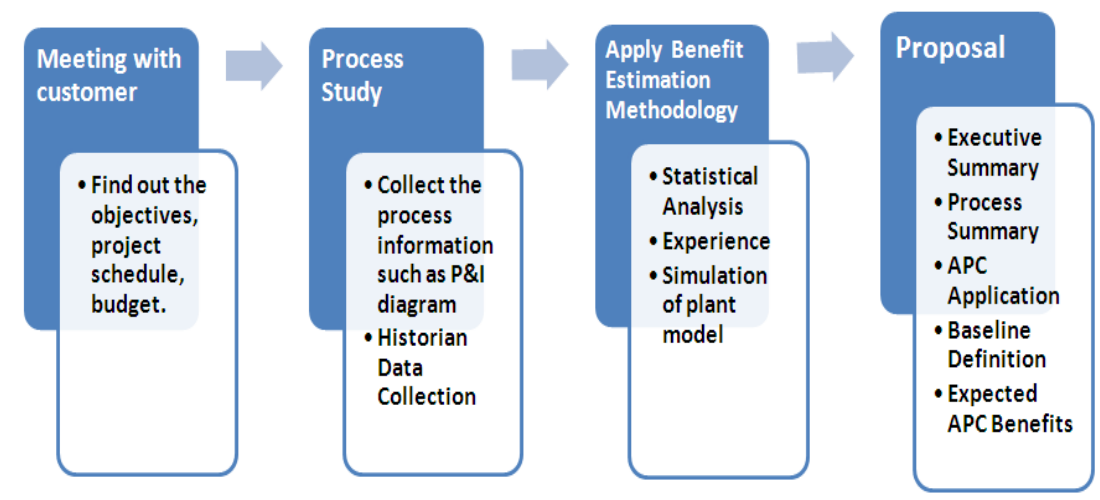

Fig. 1. Feasibility study process of APC project.

We focus on the application of benefit estimation method. Applying the Same Percentage Rule with the percentage reduction of standard deviation $(r)$ to acquire the increase of product throughput, we 
calculate the expected profit (EP, $\$ / \mathrm{yr}$ ) as follows:

$$
\mathrm{EP}=\mathrm{P} \times \mathrm{R} \times \mathrm{SR} \times \mathrm{PM}
$$

where $\mathrm{P}:$ increase product throughput (ton $/ \mathrm{hr}$ ) of plant with APC compared to that of status quo,

$\mathrm{R}$ : running hours of machine per year (hrs/yr),

SR : APC service rate $(\%)$, and

PM : Average profit margin (\$/ton).

With incremental analysis, we define "status quo" and "plant with APC" as follows. Status quo is the plant operating under DCS without APC whereas plant with APC is the plant operating with APC on top of DCS. In our incremental analysis, we use the expected profit (EP) as incremental benefit from the APC. The variation parameters for the APC benefits consist of 4 parameters. The profit margin (PM) is the external parameter embedded in the EP and is out of control. That is why we need to investigate the impact of PM onto the APC investment consideration.

For conventional financial assessment, Net Present Value (NPV) is used as a prerequisite condition and use the payback period method as complementary criterion for decision making. NPV aims to determine the financial free cash flow for each year and the sensible discount rate to discount cash flow back to net present value. First, we compute the weighted average cost of capital (WACC, \%) by using the data from annual report of the company and calculate the NPV of the APC project. In particular, we employ the expected profit from the previous study as the free cash flow (FCF) and choose a project lifetime and an investment cost. NPV is equal to the net result of the accumulated present value (PV) of free cash inflow and the PV of cash outflow. NPV is calculated as follows:

$$
N P V=\sum_{t=1}^{T} \frac{F C F_{t}}{(1+W A C C)^{t}}-K
$$

where $N P V=$ net present value of the APC project $(\mathrm{M} \$)$;

$F C F_{t}=$ free cash flow of APC project at year $t(\mathrm{M} \$)$;

$T=$ project lifetime, which is equivalent to time to expiration (yr);

$K=$ initial investment of APC project (M $\$$ ).

The prerequisite condition of the financial assessment is based on the NPV. If NPV is positive which means the combined PV of all cash inflows exceeds the PV of cash outflows, then the project is feasible. Otherwise, the project is not feasible. The initial investment cost depends on the selected APC technology and we can obtain $K$ from the vendor. Next, we calculate the payback period (PB) as follows:

$$
\mathrm{PB}=(\mathrm{K} / \mathrm{EP}) \times 12
$$

where $\mathrm{PB}$ is the payback period in months. Note that when PM turns out to be a negative value, a calculated EP becomes negative value. In such a case, Eq. (7) will be replaced by $\max (0,(\mathrm{~K} / \mathrm{EP}) \times 12)$. $\mathrm{PB}$ is an industrial practice of financial assessment that has been used among the APC vendors [17]. PB is used as one of the benchmark criteria on the typical industrial payback period for many industries such as oil and gas, refinery, chemical, petrochemical, mining, pulp and paper, power and utilities. PB is a complementary criterion of investment decision making. The typical payback period for APC project is as shown in Table 1 will be used to compare with the calculated payback period and gives a decision of "Go" or "No Go". If the calculated payback period is within the range of average payback period, then it is recommended to make 'Go' decision, otherwise the recommendation is 'No Go'. However, the current practice usually uses only a snapshot calculation of payback period at the time of feasibility study. This calculation cannot foresee the projection of the profit margin effect. Moreover, the payback period does not support for decision making in a given time frame. Based on a snapshot calculation, the management cannot justify the right time to invest or the time to avoid the investment. In the real situation, the payback period method should take into account of economic parameters such as profit margin of product and investment cost in the payback period calculation. 
Table 1. Typical payback period for APC project from industries.

\begin{tabular}{lr}
\hline Industry & $\begin{array}{r}\text { Payback Period } \\
\text { (months) }\end{array}$ \\
\hline Oil \& Gas & $0-2$ \\
\hline Refinery & $3-6$ \\
\hline Chemical & $4-6$ \\
\hline Petrochemical & $6-8$ \\
\hline Mining & $10-12$ \\
\hline Pulp \& Paper & \\
\hline Power \& Utilities & \\
\hline
\end{tabular}

Besides the feasibility study of the investment project, it is important to consider the downside risk of the project which can be divided into the internal risk and the external risk as shown in Fig. 2. The internal downside risk is the controllable parameter which can be adjusted by the management whereas the external downside risk is the uncontrollable parameter. For the APC project, P, R, and SR are controllable whereas PM is uncontrollable. To minimize the downside risk, we choose to maximize the expected benefits and take into account of the projection of PM. We apply the option to defer to the decision making process and to incorporate the flexibility of investment period whenever it is involved the uncertainty.

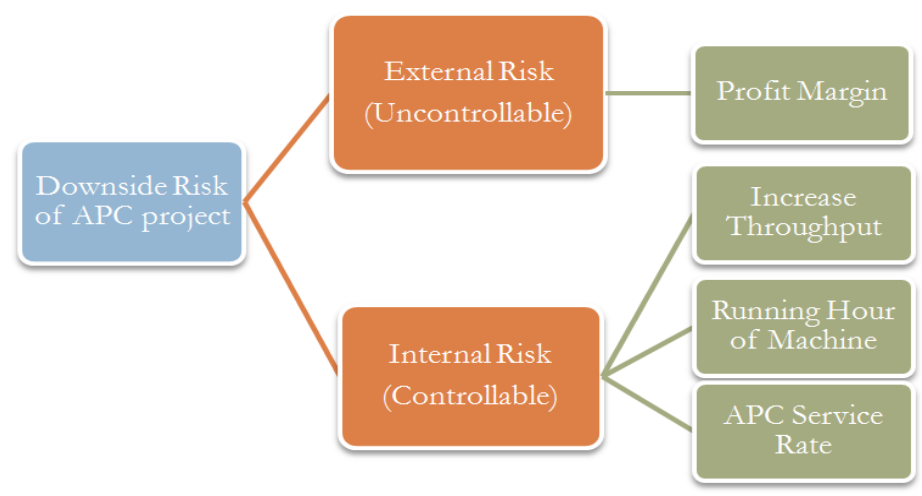

Fig. 2. Downside Risk of the APC project.

It is worth to remark when APC has been already installed in the plant. The management can justify whether the APC investment is useful by monitoring the APC service rate. It is a key performance index of the utilization of APC. If APC service rate is low, then the management should ask the operation team to investigate the root cause that prevents APC to take action. There may require retuning APC before it can be turned on.

\subsection{Gap Analysis}

The vendors of industrial process control typically use the conventional approach, such as statistical analysis, as a benefit estimation method and the result is given in terms of payback period. However, about $50 \%$ of the APC users are not satisfied with the Cost/Benefit Study that use conventional statistical analysis [2]. From the traditional payback period method, it can answer the 'Go' or 'No Go' question. Is this enough when the economic situation of the real world business is uncertain? The answer is clearly no, because the payback period is calculated using a fixed scheme. Nevertheless, the real scenario goes with the economic flow, and it involves certain dynamic parameters subject to uncertainties. Hence, we have to find how to improve the economic assessment that supports dynamic business scenarios. We review the literatures for APC feasibility study in various perspectives such as technology, financial, management and find that there are potential tools that can be applicable to APC feasibility study as shown in Table 2 . 
Table 2. Potential tools for APC feasibility study.

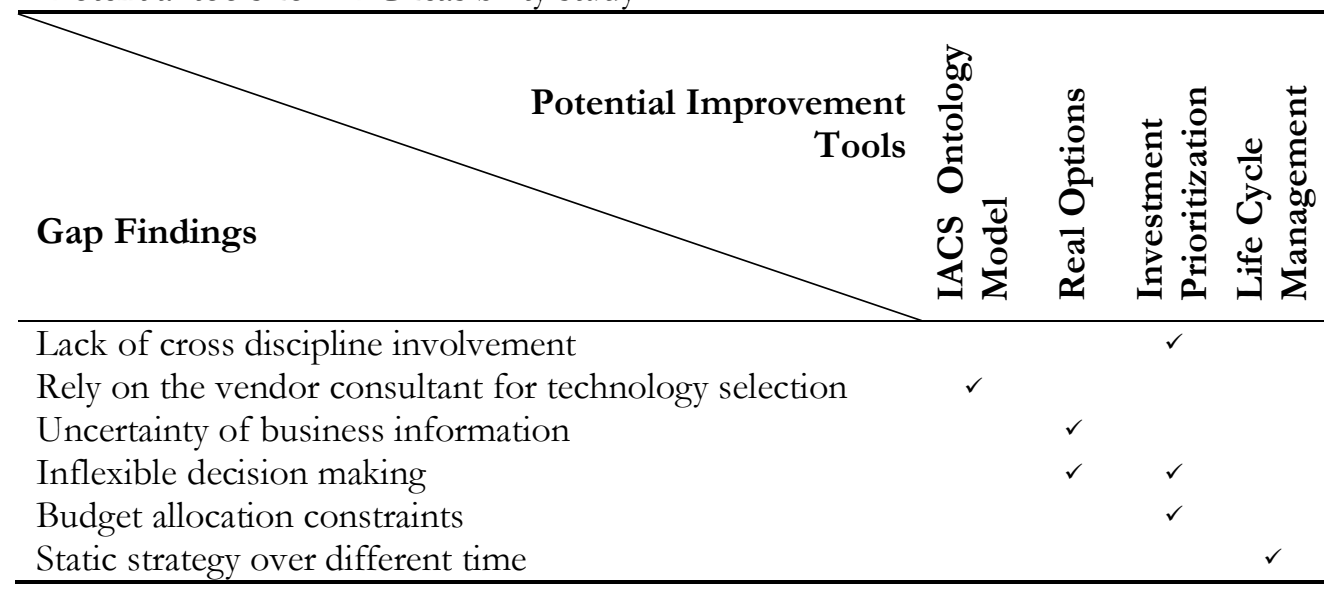

To focus on financial perspectives, real options approach has been explored [18-21]. The real options approach is capable of improving APC decision making process under economic uncertainties. In other words, the real options approach enables decision making for the investment in presence of uncertainties and provides the alternative solution. The real options approach consists of several managerial options, and two options are applicable to the APC project, namely, the option to expand and option to defer. In this paper, we will focus on the option to defer.

\section{Option to Defer}

The option to defer can provide us how to determine an appropriate time of APC investment. APC is an additional process improvement on top of the existing DCS system in the production line. APC can improve the plant operation compared to the existing production line, but APC project requires investment cost. Thus, the management should carefully determine the cost and benefit of the APC project and decide whether or not to make an investment. In particular, when there is economic uncertainty, it is important to find an effective way to determine when to invest the APC project.

From Eq. (5), we observe that PM is the external parameter of downside risk. To investigate the impact of the PM, we forecast the future PM based on time-series analysis. The accuracy of the prediction of the future PM is verified by calculation of the prediction mean squared error (PMSE). We select the optimal prediction model using the minimum PMSE compared to the actual PM. We will develop an option to defer method for the APC project and discuss its advantages in this section.

\subsection{Calculation of Assessed Values of The Investment Cost}

Rationale for increasing project cost along the decision period is the cost-time tradeoffs. Time is money, therefore extending period of investment usually incurs additional project cost. To obtain the assessed values, we need to know the initial investment cost $\left(\mathrm{K}_{0}\right)$ and company discount rate or Weighted Average Cost of Capital (WACC) rate of return. The initial investment cost $\left(\mathrm{K}_{0}\right)$ can be obtained from the vendor's quotation. We calculate the assessed value of investment cost $(\mathrm{K})$ using compound interest rate. Assume a compound interest rate as a discount rate.

$$
\mathrm{K}=\mathrm{K}_{0}\left(1+\mathrm{r}_{\text {wacc }}\right)^{\mathrm{t}}
$$

where $\quad t=$ length of time when the option is viable;

$r_{\text {wacc }}=$ company discount rate or WACC rate of return.

Assessed value of the project will be compared with the critical threshold of the investment cost to facilitate the decision making process. 


\subsection{Forecast of Profit Margin}

Next, we develop the forecast model of profit margin which will be used to determine the critical threshold of the investment cost. The forecast model of PM is obtained by applying the Box-Jenkins modeling method [22]. The autoregressive moving average (ARMA) model is chosen to generate a non-stationary series associated with model parameters $(\mathrm{p}, \mathrm{q})$. ARMA $(\mathrm{p}, \mathrm{q})$ model is defined as follows.

$$
\mathrm{F}_{\mathrm{t}+1}=\mathrm{c}+\mathrm{a}_{1} \mathrm{PM}_{\mathrm{t}}+\mathrm{a}_{2} \mathrm{PM}_{\mathrm{t}-1}+\ldots+\mathrm{a}_{\mathrm{q}} \mathrm{PM}_{\mathrm{t}-\mathrm{q}+1}+\mathrm{b}_{1} \mathrm{~F}_{\mathrm{t}}+\mathrm{b}_{2} \mathrm{~F}_{\mathrm{t}-1}+\ldots+\mathrm{b}_{\mathrm{p}} \mathrm{F}_{\mathrm{t}-\mathrm{p}+1}
$$

where $\mathrm{F}_{\mathrm{t}+1}=$ forecast profit margin at period $t+1$;

$\mathrm{PM}_{\mathrm{t}}=$ actual profit margin at period $t$;

$\mathrm{c}=$ constant;

$\mathrm{a}_{\mathrm{i}}=$ coefficient of AR;

$\mathrm{b}_{\mathrm{j}}=$ coefficient of MA;

$\mathrm{p}=$ number of coefficients of MA;

and $\quad q=$ number of coefficients of AR.

Note that $\mathrm{p}$ is to moving average (MA) order and $\mathrm{q}$ is to autoregressive (AR) order. The coefficients of ARMA model can be calculated by the least squares method [22]. For the strategies to evaluate goodness of fit of the time-series model, we use the prediction mean square error (PMSE) which measures the discrepancy between forecast outputs (validation set) and observed data (training set). Suppose the observed data is a time series of length $\mathrm{N}$. The first $\mathrm{M}$ data points are used for the training data. After fitting the model with the training data, we generate forecast values for the remaining N-M data points. PMSE can be calculated as a numerical for the predictive performance checks. The PMSE is defined as follows.

$$
\operatorname{PMSE}=\frac{1}{\mathrm{~N}-\mathrm{M}} \sum_{\mathrm{i}=\mathrm{M}+1}^{\mathrm{N}}\left(\mathrm{y}_{\mathrm{i}}-\hat{\mathrm{y}}_{\mathrm{i}}\right)^{2}
$$

where $y_{i}$ is the time series of actual PM and $\hat{y}_{i}$ is the forecast value of PM.

\subsection{Option to Defer Analysis}

As briefly reported in [23], we develop a procedure for option to defer analysis. First, we calculate the call value of the real asset. Expected future asset value:

$$
\mathrm{S}_{\text {exp }}=\mathrm{q} \mathrm{S}_{\max }+(1-\mathrm{q}) \mathrm{S}_{\min }
$$

where $S_{0}=$ present value of future cash flow from the asset;

$S_{\text {exp }}=$ expected value of the future asset;

$q, 1-q=$ up probability and down probability, respectively;

and $\quad S_{\max }, S_{\min }=$ maximum and minimum anticipated asset value at the end of the next period, respectively.

Risk-free probability:

$$
\mathrm{p}=\frac{\left(\mathrm{r}_{\mathrm{f}} \mathrm{S}_{\mathrm{exp}}\right)-\mathrm{S}_{\text {min }}}{\mathrm{S}_{\text {max }}-\mathrm{S}_{\text {min }}}
$$

where $r_{f}=$ risk free rate of return.

Call option value today:

$$
\mathrm{C}=\frac{\mathrm{pS}_{\max }+(1-\mathrm{p}) \mathrm{S}_{\min }}{\left(1+\mathrm{r}_{\mathrm{f}}^{\mathrm{t}}\right)^{2}}-\mathrm{K}\left(1+\mathrm{r}_{\text {wacc }}^{\mathrm{t}}\right)^{2}
$$

where $K=$ investment cost of APC project. Next, the critical investment cost can be calculated by setting $\mathrm{C}=0$.

$$
\frac{\mathrm{pS}_{\max }+(1-\mathrm{p}) \mathrm{S}_{\min }}{\left(1+\mathrm{r}_{\mathrm{f}}^{\mathrm{t}}\right)^{2}}-\mathrm{K}\left(1+\mathrm{r}_{\mathrm{wacc}}^{\mathrm{t}}\right)^{2}=0
$$

Solving (14) gives K' as follows: 


$$
\mathrm{K}^{\prime}=\frac{\mathrm{pS}_{\mathrm{max}}+(1-\mathrm{p}) \mathrm{S}_{\min }}{\left(1+\mathrm{r}_{\mathrm{f}}^{\mathrm{t}}\right)^{2}} /\left(1+\mathrm{r}_{\mathrm{wacc}}^{\mathrm{t}}\right)^{2}
$$

We define the critical investment cost $\mathrm{K}^{*}$ as follows:

$$
\mathrm{K}^{*}=\max \left(0, \mathrm{~K}^{\prime}\right)
$$

We can relate $\mathrm{K}^{*}$ to the external downside risk parameter using the forecast model of PM. Then, we plot $\mathrm{K}^{*}$ vs. PM. The line connecting all $\mathrm{K}^{*}$ is called the critical threshold line (CTL). Thereafter, we compare the assessed values with the CTL and use this information to decide when to defer the investment and when to invest the APC project.

\section{Decision criterion to defer the investment:}

The area above or on the CTL is considered as 'Defer to Invest' zone. If $\mathrm{K}$ is located in the 'Defer to Invest' zone, it means that $\mathrm{K}^{*}-\mathrm{K}$ is zero or negative. If the assessed value appears to be in this 'Defer to Invest' zone, the firm should defer to invest in the APC project until a better scenario is possible in the future. We recommend defer to invest in the APC project when the assessed value is located above or on the CTL.

\section{Decision criterion to invest the APC project:}

The area below the CTL is considered as 'Invest in APC' zone. If the assessed value lies in the 'Invest in APC' zone, the firm can use the decision criterion when to invest to facilitate decision making process. From the critical investment cost $\left(\mathrm{K}^{*}\right)$, we map the forecast PM for each period with $\mathrm{K}^{*}$. Then, we plot the assessed value $(K)$ over time in the same figure. We calculate the value of $\mathrm{K}^{*}-\mathrm{K}$ and plot these values over time. This line is called 'Decision Line' (DL) and used to decide when the right time to invest the APC project is. If the decision to invest is an annual practice, we recommend to invest in the period which $\left(\mathrm{K}^{*}\right.$ $\mathrm{K})$ has maximum positive value. The benefit of the real option approach relies on the accuracy of the forecast model of PM. For validation of decision making using the option to defer method, we will use the actual data of PM and apply the proposed option to defer method in comparison with the forecast data of PM.

\subsection{Advantages of Option to Defer}

All business decisions can be considered as options. The real options method provides a more flexible approach to value the real asset investments such as project investment. The enhancement of real options approach is to maximize the return from the investment by finding the best growth opportunities. From many types of real options, we apply option to defer as it considered as advanced financial assessment tool of 'binomial option pricing model' (BOPM) introduced by Cox, Ross and Rubinstein [20]. Table 3 shows a comparison of financial assessment methods.

Table 3. Comparison of financial assessment methods.

\begin{tabular}{lcr} 
Benefit Estimation Method & $\begin{array}{c}\text { Answer } \\
\text { 'Go/No Go' } \\
\text { question }\end{array}$ & $\begin{array}{r}\text { Provide best } \\
\text { alternatives of } \\
\text { the investment }\end{array}$ \\
\hline Net Present Value & Yes & No \\
Payback period & Yes & No \\
Option to defer & Yes & Yes \\
\hline
\end{tabular}

Option to defer can support the management decision to wait before taking an action until more information is known or timing is expected to be more favorable. The option to defer method can support the decision making process. In particular, it addresses when we should defer the investment until future information reduces economics uncertainty. Hence, the option to defer will be used to justify the delay of the project under economics crisis. 
The APC operation has the benefit on top of the existing process operation with DCS. However, the benefit comes with the cost and the management needs to justify that the investment with budget constraint. We already describe the economic parameters that affect the incremental benefit of the APC investment. An important benefit of the option to defer method is the flexibility of decision making to the management. The flexibility of APC investment is embedded in the call value of APC. Before expiration period, the management can decide whether to exercise the APC investment by exploring the value of 'call option today'. However, the cost of APC project is another important variable to be considered in deciding the investment. Thus, we use option to defer approach to find the critical investment cost. The option to defer method can answer when we should defer the investment and when the appropriate time to invest APC project is. This approach gives the flexibility for the management to exercise the investment decision.

\section{Case Study}

We select an ethylene plant in Rayong, Thailand that applies feasibility study with the conventional approach, namely, NPV and payback period, during the year 2009. The typical project objectives include:

- Olefin product maximization,

- Steam savings, and

- Butadiene maximization.

We will demonstrate how to adopt option to defer to recommend when to defer the investment and when to optimize the investment, and then compare the result from the payback period method. In the case study, there is serious economic crisis in year 2009. PM is vastly fluctuated over the period and changed to negative value which makes EP to be negative.

\section{1. $\quad$ Assessed Value}

We assume that investment cost of APC project starts from $2 \mathrm{M} \$$. We use corporate discount rate in the case study as a compound interest rate, $r_{\text {wacc }}=6.28 \%$, and use Eq. (8) to calculate assessed values of investment cost $(\mathrm{K})$. The assessed values can be acquired as shown in Table 4.

Table 4. Actual PM and forecast PM and assessed values of investment cost.

\begin{tabular}{|c|c|c|c|c|c|c|c|c|c|c|c|c|}
\hline $\begin{array}{c}\text { Quarter/ } \\
\text { year }\end{array}$ & $\begin{array}{l}\text { Q1/ } \\
2009 \\
\end{array}$ & $\begin{array}{l}\text { Q2/ } \\
2009\end{array}$ & $\begin{array}{l}\text { Q3/ } \\
2009 \\
\end{array}$ & $\begin{array}{l}\text { Q4/ } \\
2009\end{array}$ & $\begin{array}{l}\text { Q1/ } \\
2010\end{array}$ & $\begin{array}{l}\text { Q2/ } \\
2010\end{array}$ & $\begin{array}{l}\text { Q3/ } \\
2010 \\
\end{array}$ & $\begin{array}{l}\text { Q4/ } \\
2010 \\
\end{array}$ & $\begin{array}{l}\text { Q1/ } \\
2011\end{array}$ & $\begin{array}{l}\text { Q2/ } \\
2011\end{array}$ & $\begin{array}{l}\text { Q3/ } \\
2011 \\
\end{array}$ & $\begin{array}{l}\text { Q4/ } \\
2011 \\
\end{array}$ \\
\hline $\begin{array}{c}\text { Actual PM } \\
(\$ / \text { ton })\end{array}$ & 44 & 22 & -66 & 22 & 110 & 440 & 110 & -22 & 44 & 110 & 220 & 330 \\
\hline $\begin{array}{c}\text { Forecast } \\
\text { PM } \\
\text { (\$/ton) }\end{array}$ & 27 & -72 & 23 & 31 & 105 & 260 & 133 & 5 & 109 & 207 & 265 & 307 \\
\hline $\mathrm{K}(\mathrm{M} \$)$ & 2 & 2.03 & 2.09 & 2.19 & 2.33 & 2.51 & 2.75 & 3.06 & 3.46 & 3.97 & 4.62 & 5.46 \\
\hline
\end{tabular}

\subsection{Forecast Model of Profit Margin}

\section{Step 1. Estimate PM using ARMA(p,q) model.}

We collect the historian of Ethylene Cash PM based on Naphtha feed from [24-25]. We found that naphtha crackers operate near breakeven globally with the Ethylene spreads near 7 year lows since 'Low Oil Prices' crisis in 2009. The PM has been investigated through the history over the period Q1/2004-Q4/2008 as shown in Fig. 3. 


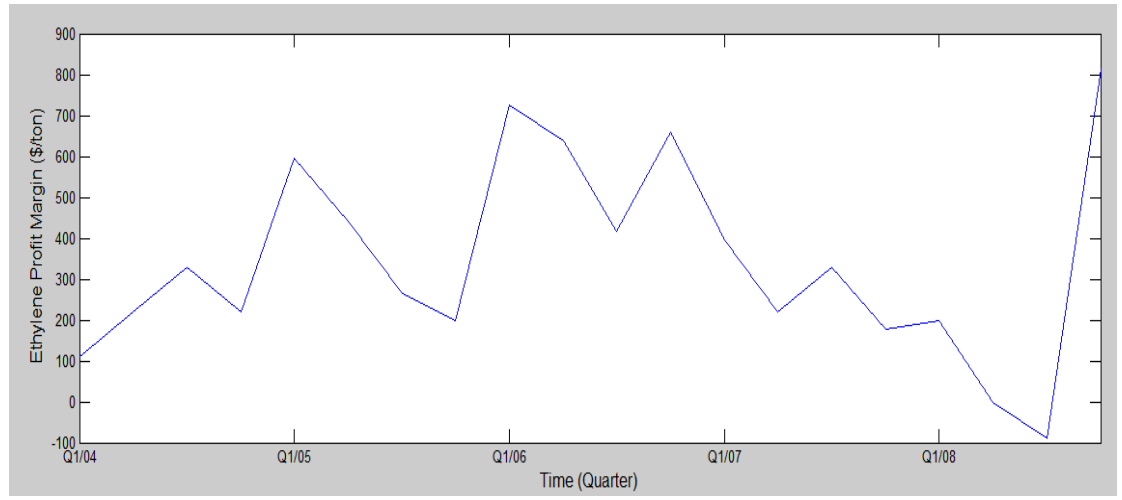

Fig. 3. History data of ethylene profit margin.

We employ ARMA function in Matlab to determine a time series model of PM. The parameters (p,q) are varied from $(1,0)$ to $(10,10)$. Then, we calculate PMSE for the time series model. From 32 samples, the first 20 observations (Q1/2004-Q4/2008) are used to determine the model. The remaining 12 samples from Q1/2009-Q4/2011 are used for validation. We search for the best fit with the minimum PMSE for validation period as shown in Table 5 .

Table 5. PMSE of ARMA model.

\begin{tabular}{ccc}
\hline Rank & ARMA & PMSE \\
\hline 1 & $(8,1)$ & $5.57 \mathrm{E}+03$ \\
2 & $(9,1)$ & $9.32 \mathrm{E}+03$ \\
3 & $(9,6)$ & $1.56 \mathrm{E}+04$ \\
4 & $(10,4)$ & $1.73 \mathrm{E}+04$ \\
5 & $(10,0)$ & $2.16 \mathrm{E}+04$ \\
\hline
\end{tabular}

\section{Step 2. Select the best ARMA model}

The ARMA $(8,1)$ model provides the lowest PMSE value at 5.57E+03. Hence, ARMA $(8,1)$ will be used to estimate PM as follows:

$$
\begin{aligned}
\mathrm{F}_{\mathrm{t}+1} & =63.82+0.89 \mathrm{PM}_{\mathrm{t}}-0.09 \mathrm{PM}_{\mathrm{t}-1}+0.13 \mathrm{PM}_{\mathrm{t}-2}+0.03 \mathrm{PM}_{\mathrm{t}-3}+0.09 \mathrm{PM}_{\mathrm{t}-4} \\
& +0.10 \mathrm{PM}_{\mathrm{t}-5}-0.21 \mathrm{PM}_{\mathrm{t}-6}-0.19 \mathrm{PM}_{\mathrm{t}-7}-\mathrm{F}_{\mathrm{t}}
\end{aligned}
$$

Then, we plot the forecast PM using $\operatorname{ARMA}(8,1)$ model and compare with other ARMA models in the same chart with the actual PM. The results are shown in Fig. 4. It can be seen that forecast PM using $\operatorname{ARMA}(8,1)$ is fluctuated along the periods of study and follows the actual PM.

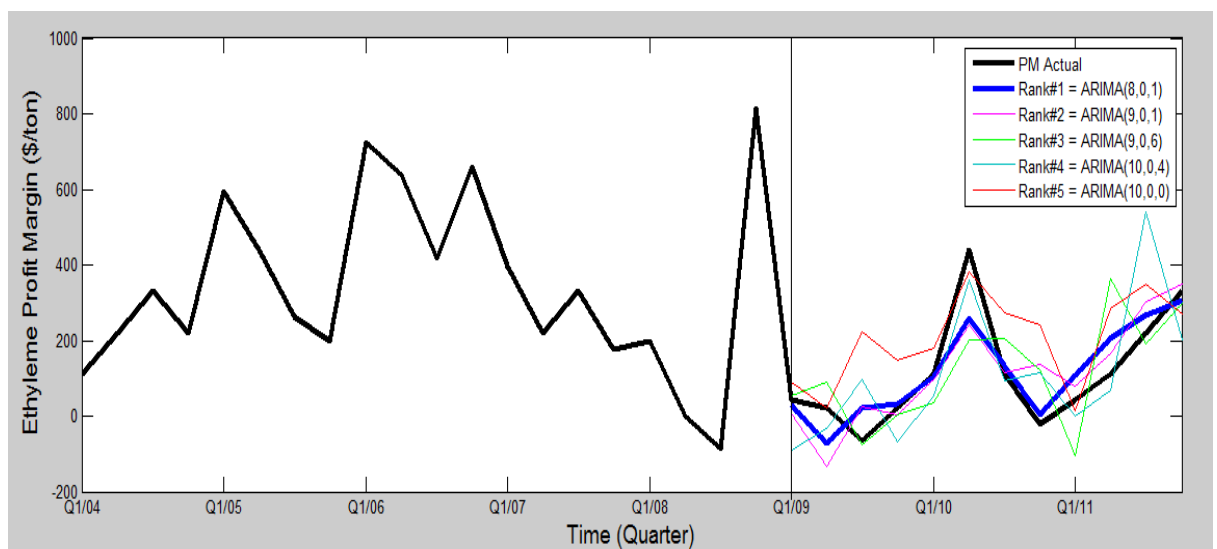

Fig. 4. Forecast PM from the ARMA model. 


\subsection{Conventional Financial Assessment}

\section{Net Present Value}

The additional benefit of APC on top of the existing ethylene plant production referred to 'Increase Throughput' $(P)$ comes from the site survey of the plant operation. In the case study with ethylene plant, the benefit of APC application to olefins product maximization gives additional $4 \%$ throughput, compared to the existing capacity. We apply Eq. (3) with the assumption of the same percentage rule and consider a $4 \%$ reduction of standard deviation $(r)$. We measure the flow rate to each furnace and get the hydrocarbon flow rate of the totalizer at 174 tons/hr. An increase of hydrocarbon flow rate, also known as increase throughput, is equal to 6.96 tons/hr. In addition, we consider the lifetime of APC project to be 7 years which is the migration period to replace the hardware PC, Windows OS and APC software with the latest release. The additional benefit of APC on top of the existing ethylene plant production is calculated using Eq. (5). From Eq. (5), we use $P=6.96$ tons $/ \mathrm{hr}, R=8,000 \mathrm{hrs} / \mathrm{yr}, S R=95 \%$. From the rolling of forecast PM for next 7 years, we calculate the EP by using Eq. (5).

Based on EP in Eq. (5), PM is the economic parameter which affects the APC investment and creates uncertainty of the investment. We determine the distribution of the return of APC project and the projection of PM over the range of time. Figure 5 shows the forecast ethylene profit margin and expected profit projection starting from 2009. We see that EP of the APC investment directly varies with the forecast PM. To compute NPV in a quarterly basis, the project lifetime of 7 years is equivalent to 28 quarters and $r_{\text {wacc }}=6.28 \%$ per year is equivalent to $r_{\text {wacc }}=1.5343 \%$ per quarter. Free cash flow (FCF) of APC project is calculated over the period of 28 quarters. We observe that the NPV method always gives a feasible decision since most of the free cash flow is usually positive during the decision timeline.

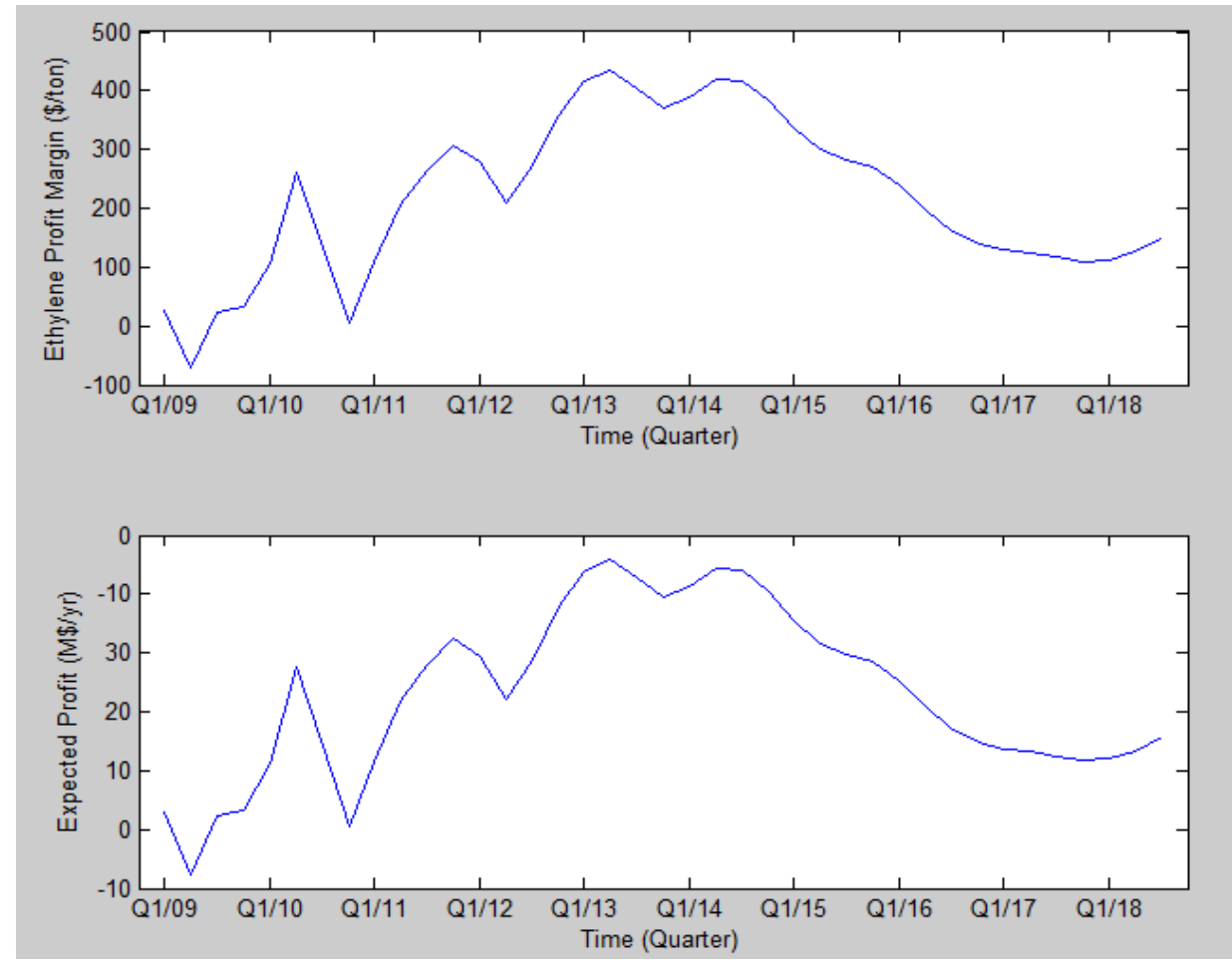

Fig. 5. The forecast PM and expected profit of the APC investment.

\section{Payback Period}

We calculate EP by using PM and $\mathrm{K}$ from Table 4. Using Eq. (7) gives the payback period shown in Table 6. The payback period should be a positive value. When the PM is negative, the payback period is not applicable (N/A). Note that the typical payback period of APC project in the petrochemical industry, as shown in Table 1, is 4-6 months. In Table 6, "Go" indicates that the investment is feasible and "No" shows that the investment is not feasible. The payback period method gives different results in different quarters. 
Comparing the forecast PM and actual PM to calculate the payback period, we observe that most cases have the same results. Only in Q2/2011 the decision result is different. It is an indicator that the forecast PM derived from ARMA forecast is quite reliable compared to the actual PM. Both NPV and payback period methods can answer 'is it feasible to invest?' but cannot answer 'when is the best period to invest?' because the payback period method considers a snapshot of decision making and applies the first 'Go' to support the investment decision.

Table 6. NPV and Payback period calculation and decision using forecast PM and actual PM.

\begin{tabular}{|c|c|c|c|c|c|c|c|c|c|c|}
\hline Time & $\begin{array}{c}\mathrm{K} \\
(\mathbf{M} \$)\end{array}$ & $\begin{array}{c}\text { Forecast } \\
\text { PM } \\
\text { (\$/ton) }\end{array}$ & $\begin{array}{l}\text { NPV } \\
\text { (M\$) }\end{array}$ & $\begin{array}{c}\mathrm{EP} \\
(\mathbf{M} \$ / \mathrm{yr})\end{array}$ & $\begin{array}{c}\text { Payback } \\
\text { Period } \\
\text { (month) }\end{array}$ & $\begin{array}{l}\text { Deci- } \\
\text { sion }\end{array}$ & $\begin{array}{c}\text { Actual } \\
\text { PM } \\
\text { (\$/ton) }\end{array}$ & $\underset{(M \$ / y r)}{E P}$ & $\begin{array}{c}\text { Payback } \\
\text { Period } \\
\text { (month) }\end{array}$ & $\begin{array}{c}\text { Deci- } \\
\text { sion }\end{array}$ \\
\hline Q1/2009 & 2 & 27 & 66.74 & 1.43 & 17 & No & 44 & 2.33 & 10 & No \\
\hline Q2/2009 & 2.03 & -72 & 69.45 & -3.81 & $\mathrm{~N} / \mathrm{A}$ & No & 22 & 1.16 & 21 & No \\
\hline Q3/2009 & 2.09 & 23 & 73.10 & 1.22 & 21 & No & -66 & -3.49 & $\mathrm{~N} / \mathrm{A}$ & No \\
\hline Q4/2009 & 2.19 & 31 & 75.23 & 1.64 & 16 & No & 22 & 1.16 & 23 & No \\
\hline Q1/2010 & 2.33 & 105 & 77.06 & 5.55 & 5 & Go & 110 & 5.82 & 5 & Go \\
\hline Q2/2010 & 2.51 & 260 & 77.83 & 13.75 & 2 & Go & 440 & 23.27 & 1 & Go \\
\hline Q3/2010 & 2.75 & 133 & 76.51 & 7.04 & 5 & Go & 110 & 5.82 & 6 & Go \\
\hline Q4/2010 & 3.06 & 5 & 76.68 & 0.26 & 139 & No & -22 & -1.16 & $\mathrm{~N} / \mathrm{A}$ & No \\
\hline Q1/2011 & 3.46 & 109 & 78.38 & 5.77 & 7 & No & 44 & 2.33 & 18 & No \\
\hline Q2/2011 & 3.97 & 207 & 78.67 & 10.95 & 4 & Go & 110 & 5.82 & 8 & No \\
\hline Q3/2011 & 4.62 & 265 & 77.68 & 14.02 & 4 & Go & 220 & 11.64 & 5 & Go \\
\hline Q4/2011 & 5.46 & 307 & 75.92 & 16.24 & 4 & Go & 330 & 17.46 & 4 & Go \\
\hline
\end{tabular}

\subsection{Option to Defer Analysis}

Next, we apply option to defer analysis to the case study. We choose $\mathrm{q}=0.5, r_{f}=4 \%, r_{\text {wacc }}=6.28 \%$, then calculate expected asset value from Eq. (11). Using Eq. (12) gives risk-free probability (p) equal to 0.20. Call option value today can be calculated as Eq. (13). Applying Eq. (14) with the PM variation, we calculate $\mathrm{K}^{*}$. Call option will have a premium value when the call option value today is positive. The call option today is calculated for two investment scenarios, $\mathrm{K}_{\min }=2 \mathrm{M} \$$ and $\mathrm{K}_{\max }=5.46 \mathrm{M} \$$, and the results are displayed in Table 7 and Fig. 6. It is apparently observed that the call option today begins to be a premium value when the PM is greater than $23 \$ /$ ton with a minimum investment of $2 \mathrm{M} \$$.

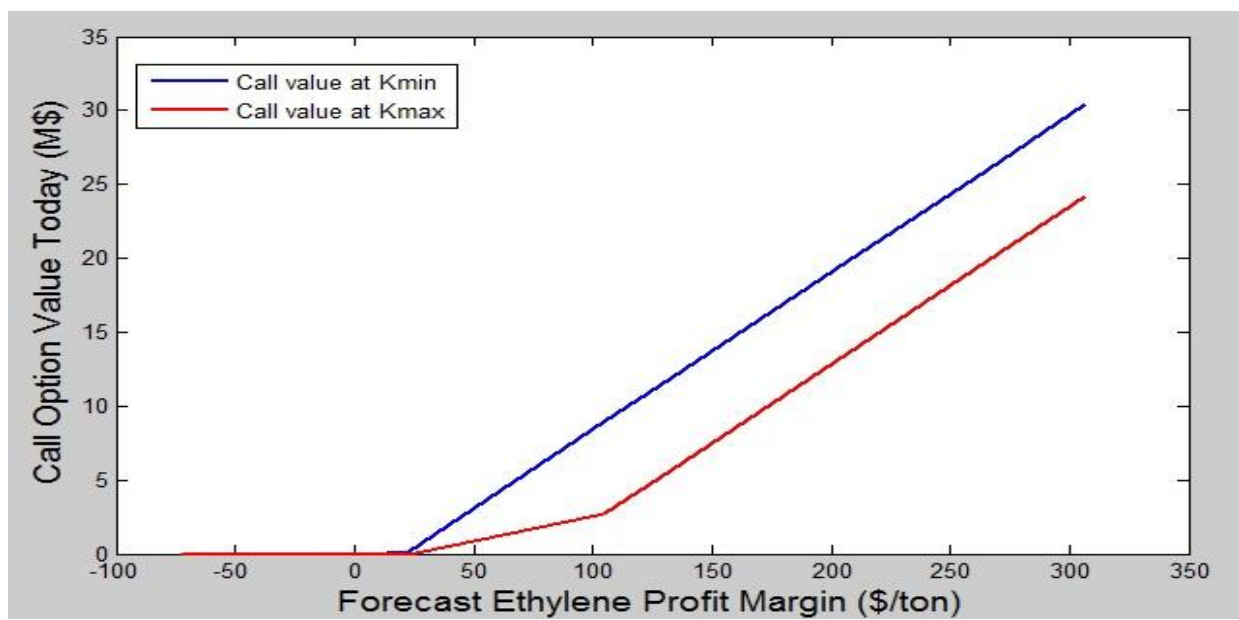

Fig. 6. Call option value today vs. profit margin. 
Table 7. Option to defer calculation.

\begin{tabular}{|c|c|c|c|c|c|c|c|}
\hline \multirow{2}{*}{$\begin{array}{l}\text { Forecast } \\
\text { Profit } \\
\text { Margin } \\
\text { (\$/ton) }\end{array}$} & \multicolumn{2}{|c|}{ Present Value of Asset } & \multirow{2}{*}{$\begin{array}{l}\text { Risk Free } \\
\text { Probability }\end{array}$} & \multirow{2}{*}{$\begin{array}{l}\mathrm{S}_{\exp } \\
(\mathrm{M} \$)\end{array}$} & \multirow{2}{*}{$\begin{array}{c}\text { Call Option } \\
\text { Value Today } \\
\text { for } \\
\mathbf{K}=2 \mathrm{M} \$\end{array}$} & \multirow{2}{*}{$\begin{array}{c}\text { Call Option } \\
\text { Value Today } \\
\text { for } \\
\mathrm{K}=5.46 \mathrm{M} \$\end{array}$} & \multirow{2}{*}{$\begin{array}{c}\text { Critical } \\
\text { Investmen } \\
\text { Cost } \mathrm{K}^{*} \\
(\mathrm{M} \$)\end{array}$} \\
\hline & $\mathrm{S}_{\min }(\mathrm{M} \$)$ & $\mathrm{S}_{\max }(\mathrm{M} \$)$ & & & & & \\
\hline-72 & 6.42 & -27.37 & 0.20 & -10.47 & 0.00 & 0.00 & 0.00 \\
\hline 5 & -0.45 & 1.90 & 0.20 & 0.73 & 0.00 & 0.00 & 0.47 \\
\hline 23 & -2.05 & 8.74 & 0.20 & 3.35 & 0.19 & 0.00 & 2.17 \\
\hline 105 & -9.36 & 39.91 & 0.20 & 15.27 & 8.93 & 2.72 & 9.91 \\
\hline 133 & -11.86 & 50.55 & 0.20 & 19.35 & 11.91 & 5.70 & 12.55 \\
\hline 207 & -18.45 & 78.68 & 0.20 & 30.11 & 19.80 & 13.59 & 19.53 \\
\hline 265 & -23.62 & 100.72 & 0.20 & 38.55 & 25.98 & 19.77 & 25.00 \\
\hline 307 & -27.37 & 116.68 & 0.20 & 44.66 & 30.46 & 24.24 & 28.96 \\
\hline
\end{tabular}

We calculate critical investment cost $\left(\mathrm{K}^{*}\right)$ using the forecast PM and plot the critical investment cost and the assessed values on the same chart. We apply the option to defter with the forecast PM to determine the CTL and the results are as shown in Fig. 7. The period that should be deferred to invest is Q2/2009 and Q4/2010 since the corresponding assessed values are greater than the critical investment cost. We calculate $\left(\mathrm{K}^{*}-\mathrm{K}\right)$ to determine the period which has maximum positive value of $\mathrm{K}^{*}$ - K. Fig. 8 displays the critical investment cost using forecast PM and the assessed investment and the difference $\mathrm{K}^{*}-\mathrm{K}$ which gives the DL. The investment is typically considered by annual basis. When the management considers the investment in year 2010, they are recommended to invest in Q2/2010. On the other hand, for 2011, they should invest in Q4/2011.

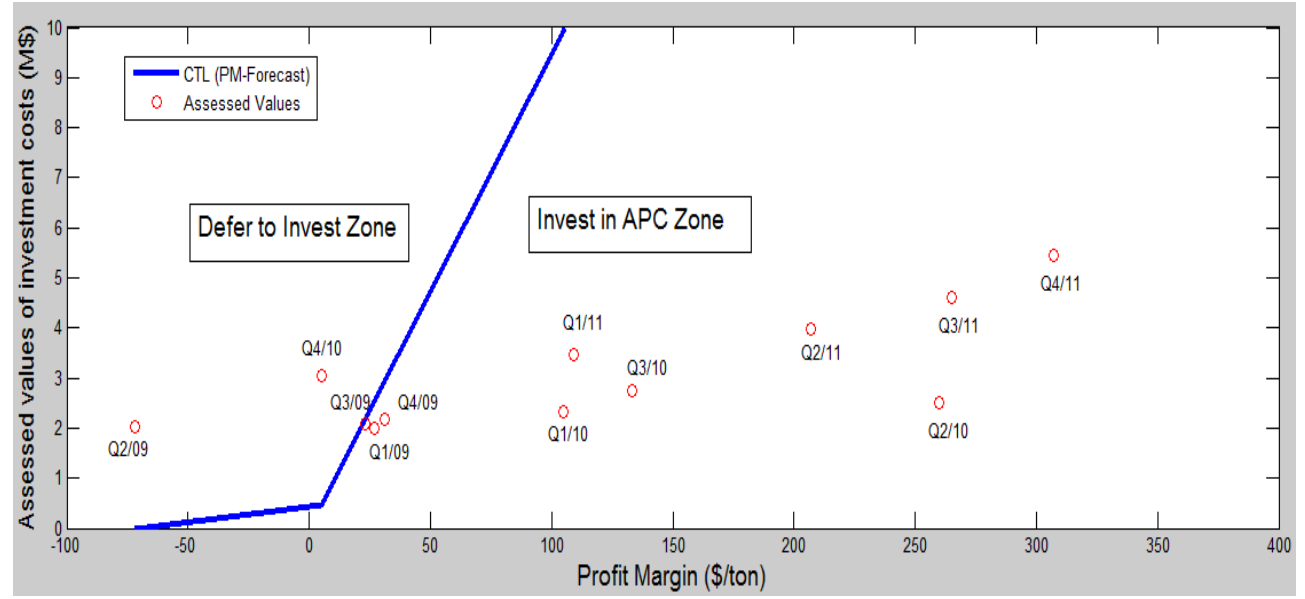

Fig. 7. Assessed values of investment cost and CTLusing forecast PM. 

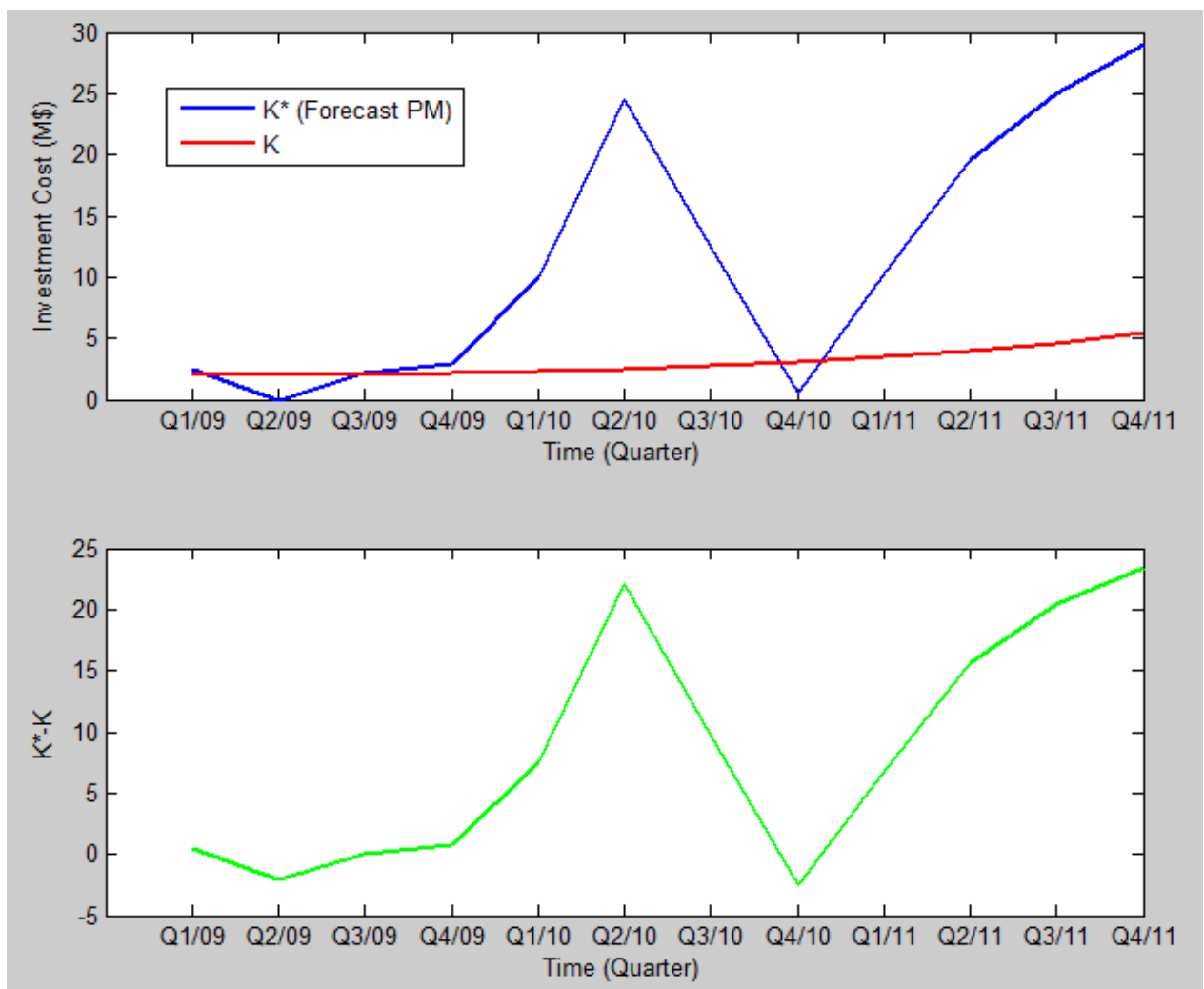

Fig. 8. Critical investment cost $\mathrm{K}^{*}$ using forecast $\mathrm{PM}$ and assessed investment cost $\mathrm{K}$ and their difference $\left(\mathrm{K}^{*}-\mathrm{K}\right)$.

For validation of the result, we apply the option to defter with the actual PM to determine the CTL and the results are as shown in Fig. 9.

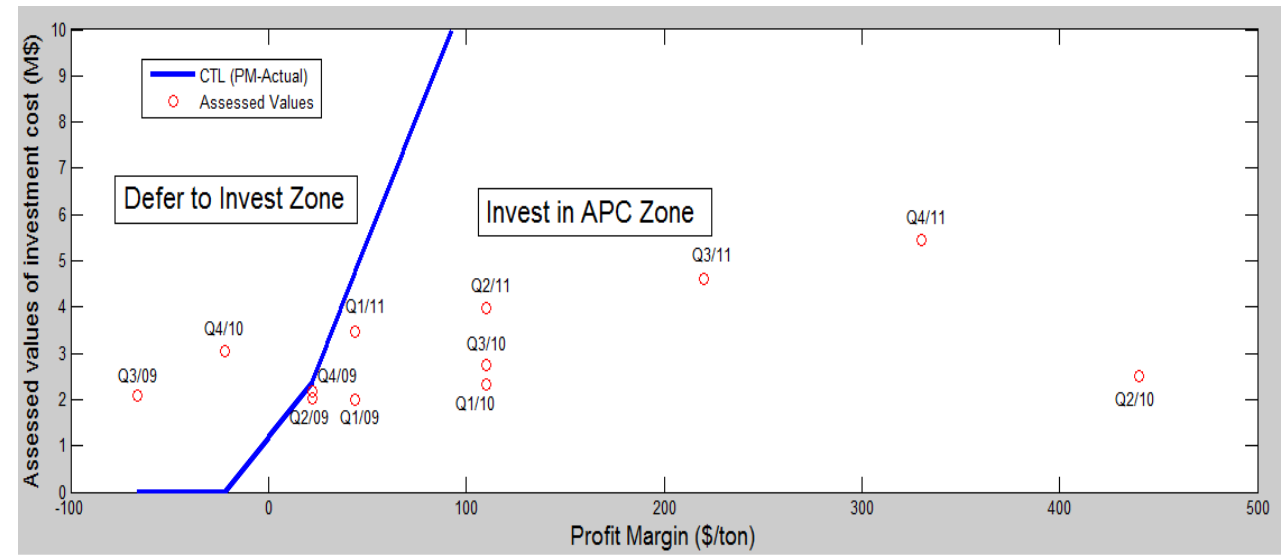

Fig. 9. Assessed values of investment cost and CTL using actual PM.

We observe that the period that the firm should defer to invest is Q3/2009 and Q4/2010 since the assessed values are above the CTL. The results are consistent to that using the forecast PM. Next, we calculate $\left(\mathrm{K}^{*}-\mathrm{K}\right)$ to determine the period which has maximum positive value of $\mathrm{K}^{*}$ - $\mathrm{K}$. Figure 10 depicts the critical investment cost using the actual PM in comparison with the assessed value of investment and the difference $\mathrm{K}^{*}-\mathrm{K}$. The decision to invest is normally made by yearly basis. When the management considers APC project in year 2010, they are recommended to invest APC in Q2/2010. On the other hand, for 2011, it is best to invest APC in Q4/2011. 

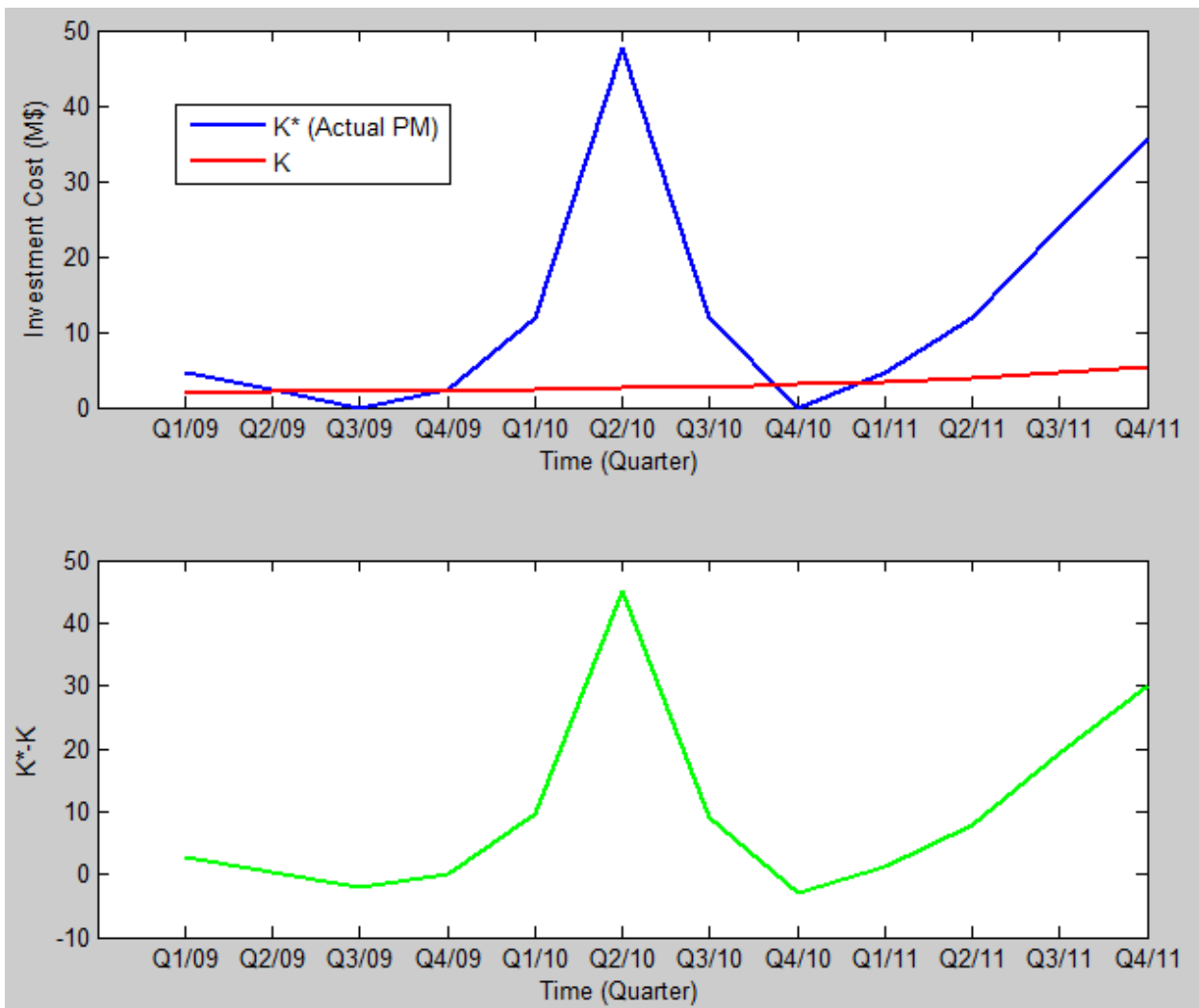

Fig.10. Critical investment cost $\mathrm{K}^{*}$ using actual $\mathrm{PM}$ and assessed investment cost $\mathrm{K}$ and their difference $\left(\mathrm{K}^{*}-\mathrm{K}\right)$.

\subsection{Discussions}

The benefit of option to defer is to make decision on the APC investment at the right time as shown in Table 8. In particular, it enables us to determine the time for APC investment where the return of $\left(\mathrm{K}^{*}-\mathrm{K}\right)$ is maximum. On the other hand, we will defer the APC investment if $\left(\mathrm{K}^{*}-\mathrm{K}\right)$ is negative value. When we apply option to defer, the management has the flexibility to choose the appropriate time to invest in APC project. The ethylene plant case study deploys APC feasibility study during the year 2009. We have the following observations.

Table 8. Result of option to defer for investment decision making.

\begin{tabular}{cc|cccc|cccc}
\hline Time & K & $\begin{array}{c}\text { Forecast } \\
\text { PM }\end{array}$ & K* & K*- K & Decision & $\begin{array}{c}\text { Actual } \\
\text { PM }\end{array}$ & $\mathbf{K}^{*}$ & K*- K & Decision \\
\hline Q1/2009 & 2.00 & 27 & 2.55 & 0.55 & & 44 & 4.75 & 2.75 & \\
Q2/2009 & 2.03 & -72 & 0.00 & -2.03 & Defer & 22 & 2.38 & 0.35 & \\
Q3/2009 & 2.09 & 23 & 2.17 & 0.08 & & -66 & 0.00 & -2.09 & Defer \\
Q4/2009 & 2.19 & 31 & 2.93 & 0.74 & & 22 & 2.38 & 0.19 & \\
Q1/2010 & 2.33 & 105 & 9.91 & 7.58 & & 110 & 11.88 & 9.55 & \\
Q2/2010 & 2.51 & 260 & 24.54 & 22.03 & Invest & 440 & 47.51 & 45.00 & Invest \\
Q3/2010 & 2.75 & 133 & 12.55 & 9.80 & & 110 & 11.88 & 9.13 & \\
Q4/2010 & 3.06 & 5 & 0.47 & -2.59 & Defer & -22 & 0.00 & -3.06 & Defer \\
Q1/2011 & 3.46 & 109 & 10.29 & 6.83 & & 44 & 4.75 & 1.29 & \\
Q2/2011 & 3.97 & 207 & 19.53 & 15.56 & & 110 & 11.88 & 7.91 & \\
Q3/2011 & 4.62 & 265 & 25.00 & 20.38 & & 220 & 23.76 & 19.14 & \\
Q4/2011 & 5.46 & 307 & 28.96 & 23.50 & Invest & 330 & 35.64 & 30.18 & Invest \\
\hline
\end{tabular}


a. During that period, there is no information that peak oil price situation followed by world economic crisis would happen. Hence, we use the PM data over last 5 years (2004-2008) to forecast the PM. Using the ARMA technique, we can predict the PM over the next 3 years (2009-2011) and put the forecast of profit margin on the chart. The minimum PMSE value shall be used to decide which ARMA model gives the best forecast of the PM.

b. Applying the ARMA model to the PM data, we notice that the results from the forecast PM and actual PM are slightly different. The accuracy of the investment decision making relies on the accuracy of PM which subsequently affects calculation of CTL and DL. From the case study, we notice that the decision to invest for forecast PM and actual PM is identical but the decision to defer has some mismatch between Q2/2009 (forecast PM) and Q3/2009 (actual PM).

c. For the payback period method, we calculate a specific payback period and apply the first 'Go' to make decision of the investment. In this case study, however, we vary profit margin (PM) and investment cost $(\mathrm{K})$ to calculate the payback period along the investment timeline to compare the result with option to defer. The payback period gives the result either 'Go' or 'No' associated with petrochemical industry. However, the questions "when to invest" and "when to defer" are still open.

d. Option to defer can facilitate the firms to answer "when to invest" and "when to defer" by making use of the forecast PM data and assessed values of the investment cost of the project.

e. APC investment with real options uses forecast PM as one of crucial parameters. The forecast PM is obtained by applying time-series analysis to the previous observed PM data (a long term historical PM data). Later, the forecast PM is applied to calculate the EP and, subsequently, to make decision of the APC investment. The investment decision does not depend on the future observed PM data, but it requires the previous observed PM data. When the PM is fluctuating during the economic crisis, it can cause the CF of the project to be negative. Note that actual PM in the case study is used only for validity test.

\section{Conclusions}

This paper proposes the real options method, especially, option to defer, for feasibility study of APC project. We demonstrate the improvement of the proposed method to ethylene plant case study which has economics uncertainty. Option to defer can be an effective financial assessment tool to support the project requirement and to make decision under economics uncertainty. It can answer 'when is the best time to invest' question. Moreover, the option to defer provides flexibility on APC project investment when additional business information is available. We currently research on options to expand with application to APC project .

\section{Acknowledgement}

The support from the 90th anniversary of Chulalongkorn University Fund (Ratchadaphisek-somphot Endowment Fund) is gratefully acknowledged.

\section{References}

[1] W. Wojsznis, A. Mehta, P. Wojsznis, D. Thiele, and T. Blevins, "Multi-objective optimization for model predictive control," IS A Transactions, vol. 46, pp. 351-361, 2007.

[2] M. Bauer and K. Craig, "Economic assessment of advanced process control," Journal of Process Control, vol. 18, pp. 2-18, 2008.

[3] W. M. Canney, "The future of advanced process control promises more benefits and sustained value," Oil \& Gas Journal, vol. 101, no. 16, pp. 48-54, 2003.

[4] B. Tinham, "Make money with advanced applications," Control and Instrumentation, vol. 27, no. 3, pp. 46-47, 1995.

[5] C. Loeblein, J. D. Perkins, B. Sriniasan, and D. Bonvin, "Economic performance analysis in the design of on-line batch optimization systems," Journal of Process Control, vol. 9, no. 1, pp. 61-78, 1991.

[6] T. E. Marlin, G. W. Barton, M. L. Brisk, and J. D. Perkins, "Advanced process control: Project report and technical papers," Technical report, Warren Centre for Advanced Engineering, Sydney, 1987. 
[7] J. L. Contreras-Dordelly and T.E. Marlin, "Control design for increased Profit," Computers \& Chemical Engineering, vol. 24, no. 2, pp. 267-272, 2000.

[8] Y. Zhou, J. Bao, P. J. McLellan, and J. F. Forbes, "Estimation of controller benefits: an optimizationbased approach," Pulp \& Paper Canada, vol. 103, pp. 23-27, 2002.

[9] Y. Zhou and J. F. Forbes, "Determining controller benefits via probabilistic optimization," International Journal of Adaptive Control and Signal Processing, vol. 17, pp. 553-568, 2003.

[10] K. R. Muske, "Estimating the economic benefit from improved process control," Industrial \& Engineering Chemistry Research, vol. 42, pp. 4535-4544, 2003.

[11] F. Xu, B. Huang, and S. Akande, "Performance assessment of model predictive control for variability and constraint tuning," Industrial \& Engineering Chemistry Research, vol. 46, pp. 1208-1219, 2007.

[12] M. Bauer, I. K. Craig, E. Tolsma, and H. de Beer, "A Profit Index for Assessing the Benefits of Process Control," Industrial \& Engineering Chemical Research, vol. 46, pp. 5614-5623, 2007.

[13] G. Martin, "Understand control benefit estimates," Hydrocarbon Process, vol. 83, no. 10, pp. 43-46, 2004.

[14] K. R. Muske and C. S. Finegan, "Analysis of a class of statistical techniques for estimating the economic benefit from improved process control," In Proceedings of the 6th International Conference on Chemical Process Control; J.B. Rawlings, B.A. Ogunnaike, J.W. Eaton, American Institute of Chemical Engineers: New York, 2002; AIChE Symposium Series 326, vol. 98, pp 408-412, 2002.

[15] T. Marlin, Process control: Designing processes and control systems for dynamic performance. New York: McGraw Hill, 1995.

[16] Lecture Notes on Assessing Economic Benefits of Advanced Control, Process Control in the Chemical Industries, Chemical Engineering Department, King Saud University, 2002.

[17] S. Crisafulli and P. Yap, Sustain Advanced Process Control Benefits, Honeywell Users Group Asia Pacific, 2012. Available: http://www.honeywellprocess.com/library/news-andevents/presentations/HUGAP-SustainAdvancedControlsBenefits.pdf

[18] M. A. Brach, Real Options in Practice. Wiley Finance, 2003.

[19] A. Damodaran, Investment V aluation, 2nd ed. Wiley Finance, 2002.

[20] J. Mun, Real Options Analysis, 2nd ed. John Wiley \& Sons, 2006.

[21] J. C. Cox, S.A. Ross, and M. Rubinstein, "Options pricing: a simplified approach," Journal of Financial Economics, vol. 7, pp. 229-263, 1979.

[22] G. E. P. Box, G. M. Jenkins, and G. C. Reinsel, Time Series Analysis: Forecasting and Control, 3rd ed., Englewood Cliffs, NJ: Prentice-Hall, 1994.

[23] A. Asawachatroj, D. Banjerdpongchai, and P. Busaratragoon. "Real options approach to estimate financial benefit of advanced process control," In Proc. of International Symposium on System Integration (SII), IEEE/SICE, Fukuoka, Japan, Dec 2012, pp. 829-834.

[24] B. Patel, Global Olefins \& Polyolefins, LyondellBasell Investor Day, December, 2010. Available: http://www.lyondellbasell.com

[25] B. Patel, Olefins \& Polyolefins -Europe, Asia and International and Technology, December, 2011. Available: http://www.lyondellbasell.com/NR/rdonlyres/F3236299-3F1A-4A6E-ADBB-

19B05137A26A/0/4Olefins_PolyolefinsEAI.pdf 
